\section{Intense warming on highland Sumatra during the mid-Holocene sea-level highstand}

\author{
PETTER LARS HÄLLBERG ${ }^{1}$, ANTONIO MARTÍNEZ \\ CORTIZAS $^{2}$, KARTIKA ANGGI HAPSARI $^{3}$, HAMDI RIFAI $^{4}$, \\ STEFFEN EISELE ${ }^{5}$, CAROLINE BOUVET DE \\ MAISONNEUVE $^{5}$ AND RIENK SMITTENBERG $^{6}$
}

${ }^{1}$ Stockholm University

${ }^{2}$ Universidade de Santiago de Compostela

${ }^{3}$ University of Goettingen

${ }^{4}$ Universitas Negeri Padang

${ }^{5}$ Nanyang Technological University

${ }^{6}$ ETH Zurich

Presenting Author: petter.hallberg@geo.su.se

The Indo-Pacific Warm Pool (IPWP) climate and related monsoon systems directly affect half the global population, and knowing their past behaviour is crucial for the understanding of the climate system and potential future change. A regionally complex pattern has emerged over the last decades and there is evidence, for example, of teleconnections between polar and IPWP climate in some records, but not in others [1]. However, too few terrestrial proxy records exist in the tropics to resolve the details of IPWP climate variability. Here we present a Holocene peatland record from highland Sumatra. We use branched glycerol dialkyl glycerol tetraethers (brGDGTs), bulk and compound-specific stable isotopes, Fourier-Transform Infrared (FTIR) analysis, carbon accumulation rate and long-chain alkane distributions, augmented by pollen and geochemical analyses, to reconstruct past temperature, precipitation and environmental changes. Our results mainly reflect ENSO activity, regional temperature variations and local peatland wetness and vegetation.

Three main climate-environmental phases emerge over the Holocene: 1) Relatively cold climate and the peatland starts to form on the former shallow lake during the Early Holocene. Highly variable titanium input suggests episodic drought and slope wash events, possibly associated with increased ENSO activity. 2) A warm and wet period coinciding with the midHolocene sea-level highstand between 8 - 3 ka BP. brGDGTderived temperatures peaked around $21.7{ }^{\circ} \mathrm{C}$ at $4.7 \mathrm{ka} \mathrm{BP}, \sim 3{ }^{\circ} \mathrm{C}$ warmer than today. This coincides with the wettest conditions according to a nearby speleothem $\delta^{18} \mathrm{O}$ record [2]. 3) At $3 \mathrm{ka}$ BP, the climate abruptly deteriorated into colder and drier conditions with re-intensified ENSO activity similar to the early Holocene. Over the last centuries the temperature increased to the current $18.7^{\circ} \mathrm{C}$, matching present-day weather station data.

Figure 1 a) brGDGT-derived mean annual air temperature (MAAT) and b) bulk d13C. c) Speleothem $\delta^{18} \mathrm{O}$ from the nearby Tangga Cave ${ }^{2}$

[1] Huang et al., 2019. QSR, 1-15, 222.

[2] Wurtzel et al., 2018. EPSL, 264-278, 492.

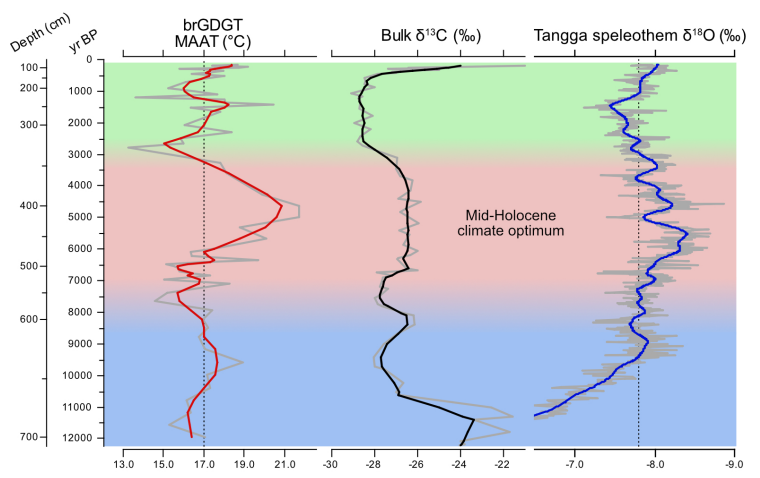

